\title{
Solar Photovoltaic Irrigation Pumping System
}

\author{
T.K. Maheshwari ${ }^{1}$, Devesh Kumar $^{2 *}$ and Manish Kumar ${ }^{2}$ \\ ${ }^{1}$ Dr. B.R.A College of Agricultural Engineering and Technology, Etawah, U.P., India \\ ${ }^{2}$ Department of Farm Machinery and Power Engineering, SHUATS, Allahabad, U.P., India \\ *Corresponding author
}

\section{A B S T R A C T}

Keywords

Photovoltaic panel, Irrigation pumps, Tube-well.

Article Info

Accepted:

17 September 2017

Available Online:

10 October 2017
A photovoltaic irrigation pump system was designed. The use of photovoltaic system reduces the load of increasing electric demand on government as it is alternative for conventional energy in agriculture sector. The Solar Photovoltaic (SPV) array converts solar energy directly into electricity as direct current (DC). The 16 to 20 solar plates in solar panel were used to cover approximately $100 \mathrm{~m}^{2}$ area along with $5 \mathrm{hp}(4800 \mathrm{~W})$ submersible to lift the water from tube-well for $80 \mathrm{ft}$ to $200 \mathrm{ft}(24 \mathrm{~m}$ to 60 $\mathrm{m}$ ) in Etawah region. The total power requirement is $7200 \mathrm{kWh}$ annually for 1500 working hours.

\section{Introduction}

The use of photovoltaic system reduces the load of increasing electric demand on government as it is alternative for conventional energy in agriculture sector. The Solar Photovoltaic (SPV) array converts solar energy directly into electricity as direct current (DC). Water pumping systems powered by solar is a clean, decentralized and economical alternative for the irrigation of crops. A benefit of using solar energy to power agricultural water pump system is that increased water requirements for livestock and irrigation tend to coincide with the seasonal increase of incoming solar energy. When properly designed, these PV systems can also result in significant long-term cost savings and a smaller environmental footprint compared to conventional power systems.
The volume of water pumped by a solar powered system in a given interval depends on the total amount of solar energy available in that period. Specially, the flow rate of the water pumped is determined by both the intensity of the solar energy available and the size of the PV array used to convert that solar energy into direct current (DC) electricity.

The principle components in a solar-powered water pump system include: The PV array and its support structure, an electrical controller, and an electric-powered pump.

\section{Materials and Methods}

The implementation of solar pumping system (Fig. 1) in Etawah region depends on: 
TDH-Total Dynamic Head (in feet).

The water source (surface or well).

The available electrical power (peak power) and energy (total energy, i.e. power $\mathrm{x}$ time) produced by the PV panel array.

The water requirement (flow rate or total volume in a given time period, including the storage requirement.

\section{Total Dynamic Head (TDH) for the pump}

The TDH for a pump is the sum of the vertical lift, pressure head, and friction loss. Friction losses apply only to the piping and appurtenances between the point of intake (inlet) and the point of storage (i.e. the storage tank or pressure tank). Flow from the storage tank to the point of use (i.e. the trough) is typically gravity fed.

Therefore, friction losses between the storage tank and the point of use are independent from the pump and do not need to be accounted for when sizing the pump.

\section{Water source}

The configuration of the water system will be defined primarily by the type of water source used, as well as by the local topography and the location(s) of the delivery point(s). The water source may be either subsurface (a well) or surface (a pond, stream, or spring). If the water source is a well, the following items will need to be determined. The static water level, pumping rate and associated drawdown (along with any seasonal variation), and the water quality.

\section{Design process}

Various design factor which are to be determined are-
Water requirement

Water source

System layout

Water storage

Solar isolation and PV panel location

Design flow rate of the pump

\section{Water requirement}

The first step in designing a solar-powered water pump system is to determine the overall water requirement for the operation.

This can be done in part by using the average water requirement values for various crops and livestock.

It can be determined by using given formula:

$\mathrm{IWR}=\mathrm{KC} \times \mathrm{ET} 0 \times \mathrm{P} \times \Delta \mathrm{S}$

Where,

IWR $=$ Water requirement in $\mathrm{mm} /$ year

$\mathrm{KC}=$ Crop coefficient

$\mathrm{ET}=$ Evapotranspiration

$\mathrm{P}=$ Precipitation

$\Delta \mathrm{S}=$ Change in storage

\section{System layout}

The third step in the system development process is to determine the layout of the entire system, including the locations and elevations of the following components:

a. Water source b. Pump c. PV panels d. Storage tanks e. Points of use (i.e. water troughs) f. Pipeline routes

\section{Water storage}

A water storage tank is normally an essential element in an economically viable solarpowered water pump system. A tank can be used to store enough water during peak 
energy production to meet water needs in the event of cloudy weather or maintenance issues with the power system.

\section{Solar insolation and pv panel location}

Appropriate data should be used to determine the amount of solar insolation (peak sun hours) available at the site.

Appropriate data on solar insolation values for different locations in Oregon may be obtained from the table or from a solar insolation program, such as the PVWATTS Beta Viewer that was developed by the NREL.

\section{Results and Discussion}

\section{Design flow rate for the pump}

The design flow rate for the pump is calculated by dividing the daily water needs of the operation by the number of peak sun hours per day. To lift the water from this given depth for approximately 5hp of submersible pump is required. Annually the working hours are calculated as 1500 . For 5 hp submersible pump running 1500 hours annually, annual energy consumption was calculated as $7200 \mathrm{kWh}$.Amount of solar radiation received by Etawah receives annually about $4.04 \mathrm{~kW} / \mathrm{m}^{2}$ on average per day.

Fig.1 Direct coupled solar pumping system

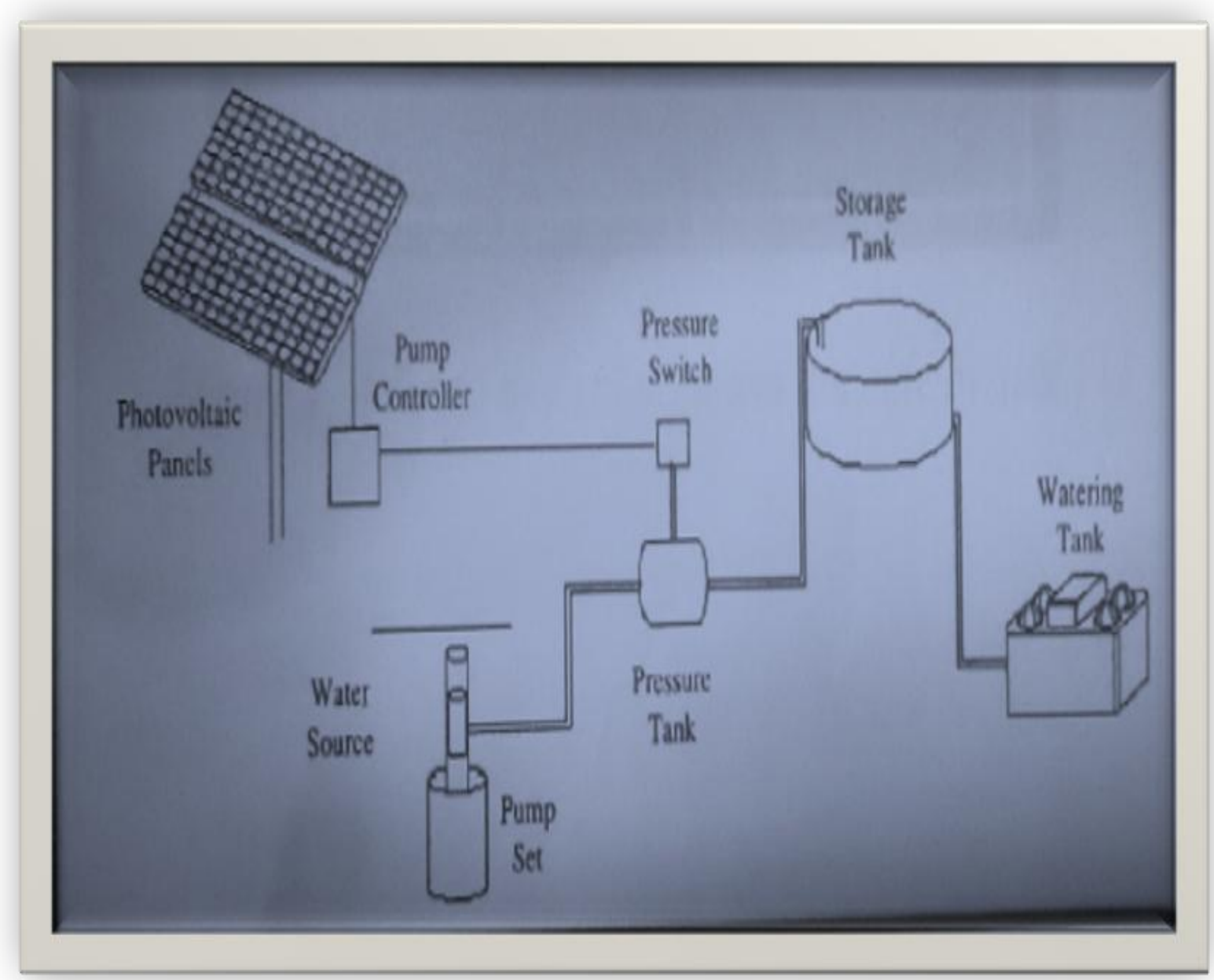


Fig.2 Solar irradiance and peak sun hours

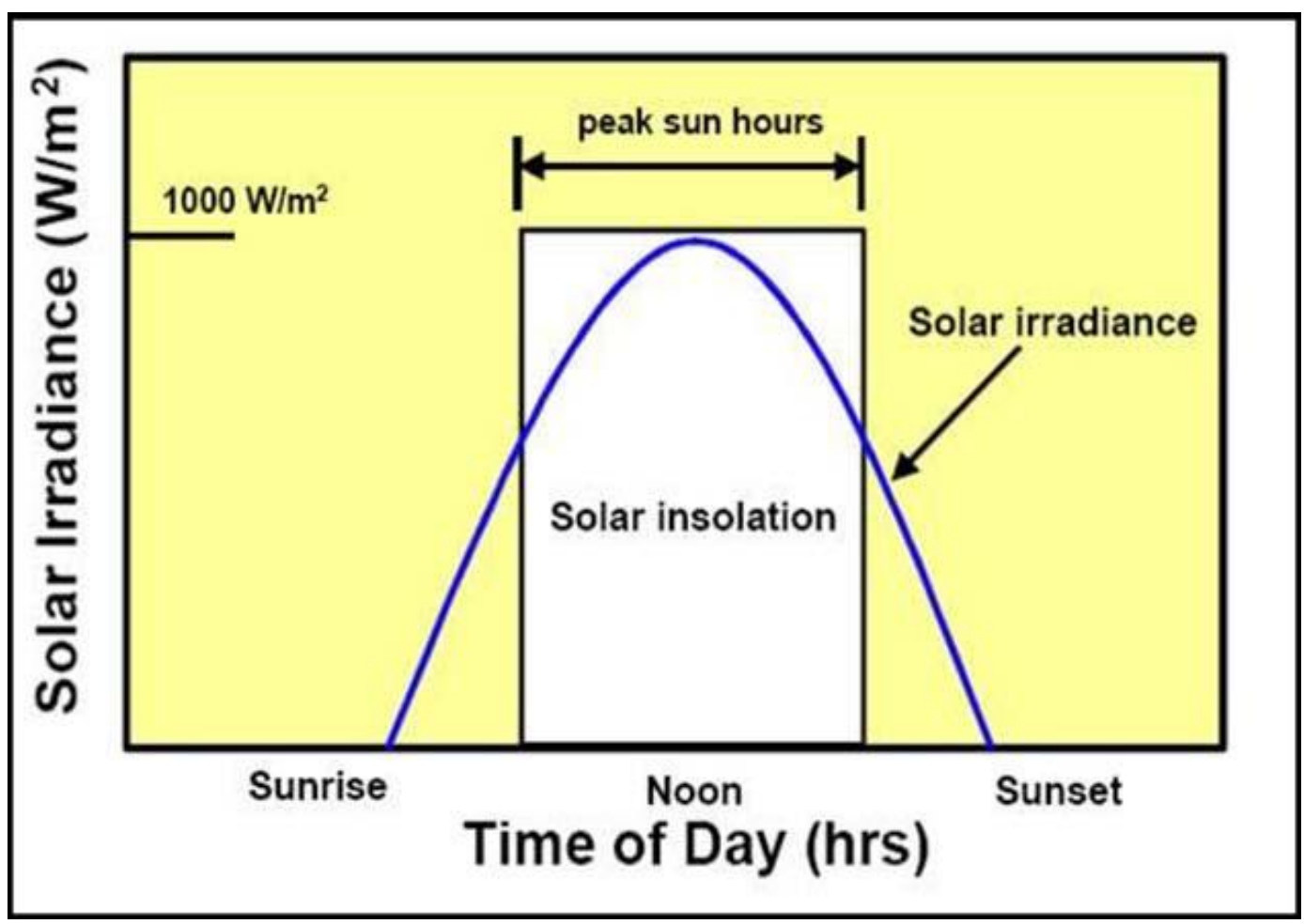

Graph.1 Average per day of solar energy per month in $\mathrm{kWh} / \mathrm{m}^{2}$

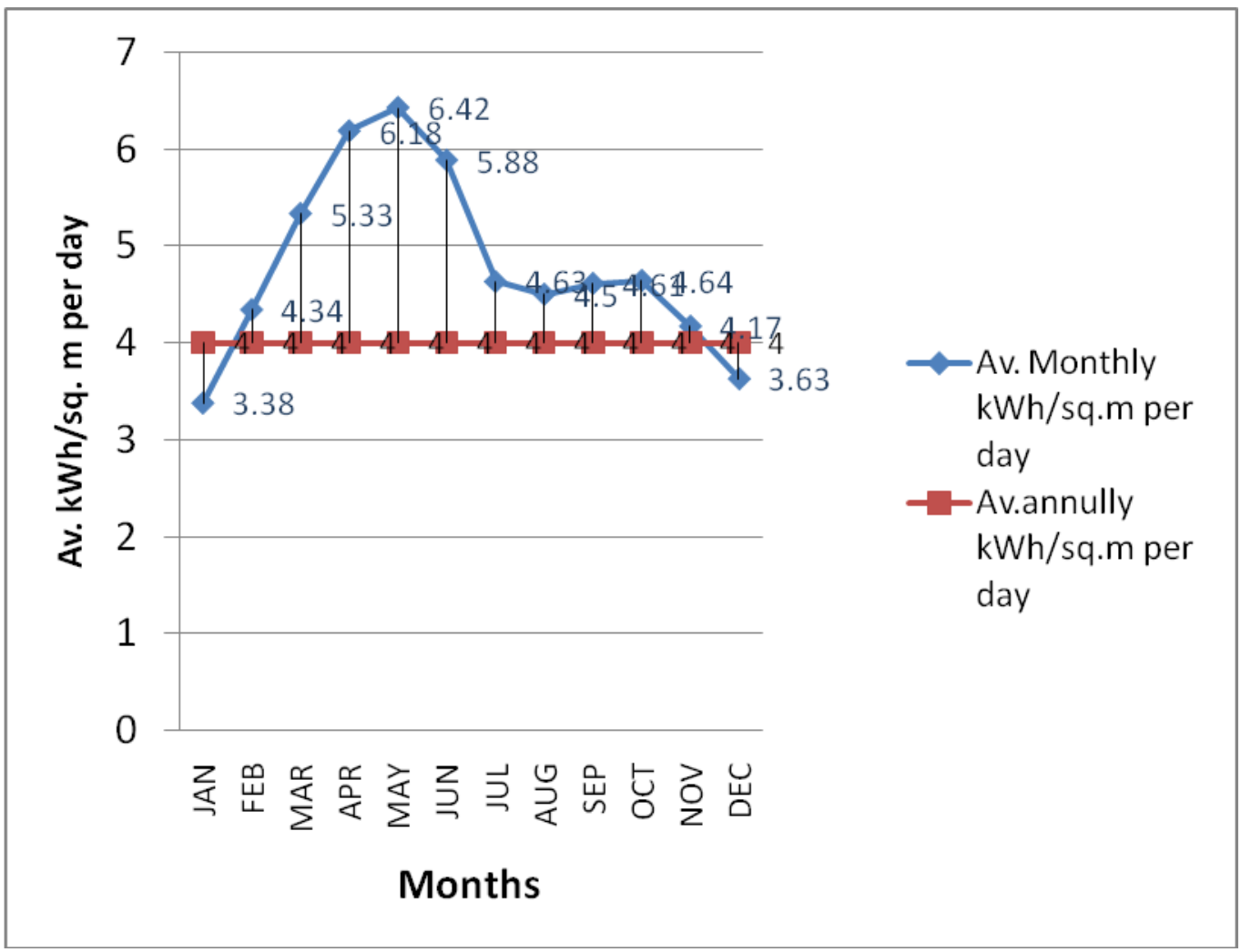


Design Flow Rate for the Pump

\begin{tabular}{|c|c|}
\hline Month & Average $\left(\mathbf{k W h} \mathbf{m}^{2}\right)$ per day \\
\hline January & 3.38 \\
\hline February & 4.34 \\
\hline March & 5.33 \\
\hline April & 6.18 \\
\hline May & 6.42 \\
\hline June & 5.88 \\
\hline July & 4.63 \\
\hline August & 4.50 \\
\hline September & 4.61 \\
\hline October & 4.64 \\
\hline November & 4.17 \\
\hline December & 3.63 \\
\hline
\end{tabular}

Annual energy consumption is of about 7200 $\mathrm{kWh}$ for single $5 \mathrm{hp}$ submersible pump, i.e. 20 $\mathrm{kWh}$ per day.

Depending upon the capacity of solar panel to produce electric energy, required number of panel can be used.

Also, the area receiving the solar radiation can be changed according to the requirement

The annual requirement of energy for $5 \mathrm{hp}$ submersible pump is about $7200 \mathrm{kWh}$ i.e. 20 $\mathrm{kWh}$ per day.

Etawah receives $4.0 \mathrm{kWh} / \mathrm{square} \mathrm{m}$ per day annually (on average).

\section{References}

Ali A.R., Rehman S., Al-Agili M.H., AlOmari M. and AlFayezi, Usage of photovoltaics in an automated irrigation system. Renewable Energy, Vol. 23, pp. 17-26, 2001.

Atul Kumara and Tara C. 2004. Kandpalb Renewable energy technologies for irrigation water pumping in India: A preliminary attempt towards potential estimation. Energy. Volume 32, Issue 5, May 2007, Pages 861-870
Atul Kumara and Tara C. 2004. Kandpalb Renewable energy technologies for irrigation water pumping in India: A preliminary attempt towards potential estimation. Energy. Volume 32, Issue 5, May 2007, Pages 861-870

Christopher W. Sinton, Roy Butler and Richard Winnett, 2005. "Guide to Solar Powered Water Pumping Systems in New York State" published by New York State Energy Research and Development Authority.

Christopher W. Sinton, Roy Butler and Richard Winnett, 2005. "Guide to Solar Powered Water Pumping Systems in New York State" published by New York State Energy Research and Development Authority.

Data taken from information given by UP government.

Indu R. Pillai and Rangan Banerjee 2008. Renewable energy in India: Status and potential. Energy Volume 34, Issue 8, August 2009, Pages 970-980

Sridharan, K.S., 2007. Lessons Learnt from Solar PV Pumping in India.

Khatib, T., 2010. Design of photovoltaic water pumping system at minimum cost for Palestine: a review. J. Appl. Sci. 10(22):2773-2784. 
Abu-Aligah, M., 2011. Design of Photovoltaic Water Pumping System and Compare it with Diesel Powered Pump. Jordan Journal of Mechanical and Industrial Engineering, page 273280, Volume 5, Issue No. 3, June.

PallavPurohit 2007. Financial evaluation of renewable energy technologies for irrigation water pumping in India.
Energy Policy. Volume 35, Issue 6, June 2007, Pages 3134-3144

Renewable Energy Primer-Solar. USDANRCS West National Technical Centre, Portland, Oregon.

Rentch, U.R.S., 1982. Solar Photovoltaic for Irrigation Water Pumping. SKAT, St. Gallen.

\section{How to cite this article:}

Maheshwari, T.K., Devesh Kumar and Manish Kumar. 2017. Solar Photovoltaic Irrigation Pumping System. Int.J.Curr.Microbiol.App.Sci. 6(10): 1884-1889. doi: https://doi.org/10.20546/ijcmas.2017.610.227 